\title{
Architecture of Chiral Poly(phenylacetylene)s: From Compressed/Highly Dynamic to Stretched/Quasi-Static Helices
}

\author{
Rafael Rodríguez, Emilio Quiñoá, Ricardo Riguera* and Félix Freire* \\ Centro Singular de Investigación en Química Biolóxica e Materiais Moleculares \\ (CIQUS) and Departamento de Química Orgánica \\ Universidade de Santiago de Compostela, 15782 Santiago de Compostela (Spain) \\ ricardo.riguera@usc.es, felix.freire@usc.es
}

Supporting Information 


\section{Contents:}

Materials and Methods $\quad$ S3

Synthesis of Monomers

CD Studies of Monomers $\quad S 14$

Synthesis of Polymers $\quad S 16$

$\begin{array}{ll}\text { GPC Studies } & \mathbf{S 1 9}\end{array}$

Circular Dichroism and Ultraviolet Studies $\quad$ S20

$\begin{array}{ll}\text { Thermal Studies } & \text { S21 }\end{array}$

$\begin{array}{ll}\text { AFM Studies } & \text { S23 }\end{array}$

Response of the Polymers to External Stimuli:

Solvents and Metal Cations $\quad$ S28

$\begin{array}{ll}\text { Supporting References } & \$ 30\end{array}$ 


\section{Materials and Methods}

CD measurements were done in a Jasco-720. The amount of polymer used for CD measurements was $0.1 \mathrm{mg} / \mathrm{mL}$.

UV spectra were registered in a Jasco V-630. The amount of polymers used for CD measurements were $0.1 \mathrm{mg} / \mathrm{mL}$.

VT-CD/VT-UV measurements were done in a Jasco-720 and a V-630 respectively with a thermostatic PolyScience programmable temperature controller system.

Raman spectra were carried out in a Renishaw confocal Raman spectrometer (Invia Reflex model), equipped with two lasers (diode laser $785 \mathrm{~nm}$ and Ar laser $514 \mathrm{~nm})$.

DSC traces were obtained in a DSC Q200 Tzero Technology (TA Instruments, New Castle, UK), equipped with a refrigerated cooling system RCS90 (TA Instruments, New Castle, UK), using a Tzero low-mass aluminum pan.

TGA traces were obtained in a TGA Q5000 (TA Instruments, New Castle, UK) using a platinum pan.

GPC studies were carried out in a Waters Alliance equipped with Phenomenex GPC columns. The amount of polymer used for GPC measurements was $0.1 \mathrm{mg} / \mathrm{mL}$.

The preparation of single molecular layers of different polymers at the air/water interface, using the LS method, was carried out by droplet-by-droplet, spreading $200 \mathrm{~mL}$ of a chloroform solution $(0.1 \mathrm{mg} / \mathrm{mL})$ on the surface of Milli-Q water in a shallow Teflon trough ( $36 \mathrm{~cm} \times 11 \mathrm{~cm} \times 1 \mathrm{~cm}$ ). The deposition was performed with a microsyringe, allowing the chloroform solution to spread and evaporate without sinking into the less dense subphase. The system was equipped with a Wilhelmy plate surface tension balance and computer-controlled barriers that allowed gradual compression of the resulting polymer film until a compact monolayer was formed (the surface pressure, i.e., the surface tension reduction, raised above zero). A feedback mechanism allows maintaining a constant surface pressure throughout the experiment.

AFM measurements were performed in a MultiMode V Scanning Probe Microscope (Veeco Instruments) in air at rt with standard silicon cantilevers and super-sharp cantilevers in tapping mode using $12 \mu \mathrm{m}$ and $1 \mu \mathrm{m}$ scanners. Nanoscope 
processing software and WSxM 4.0 Beta 1.0 [4] (Nanotec Electronica, S.L.) were used for image analysis.

SEM measurements were performed on a LEO-435VP electron microscope equipped with an energy dispersive X-ray (EDX) spectrometer. A drop of a solution of different polymers $(0.1 \mathrm{mg} / \mathrm{mL})$ was settled on a silicon wafer chip (Ted Pella, Inc.), and allowed to dry at rt for $12 \mathrm{~h}$.

For molecular modeling we used Spartan 10 (MMFF94). As a molecular visualization system we used PyMOL. 


\section{Synthesis of Monomers}

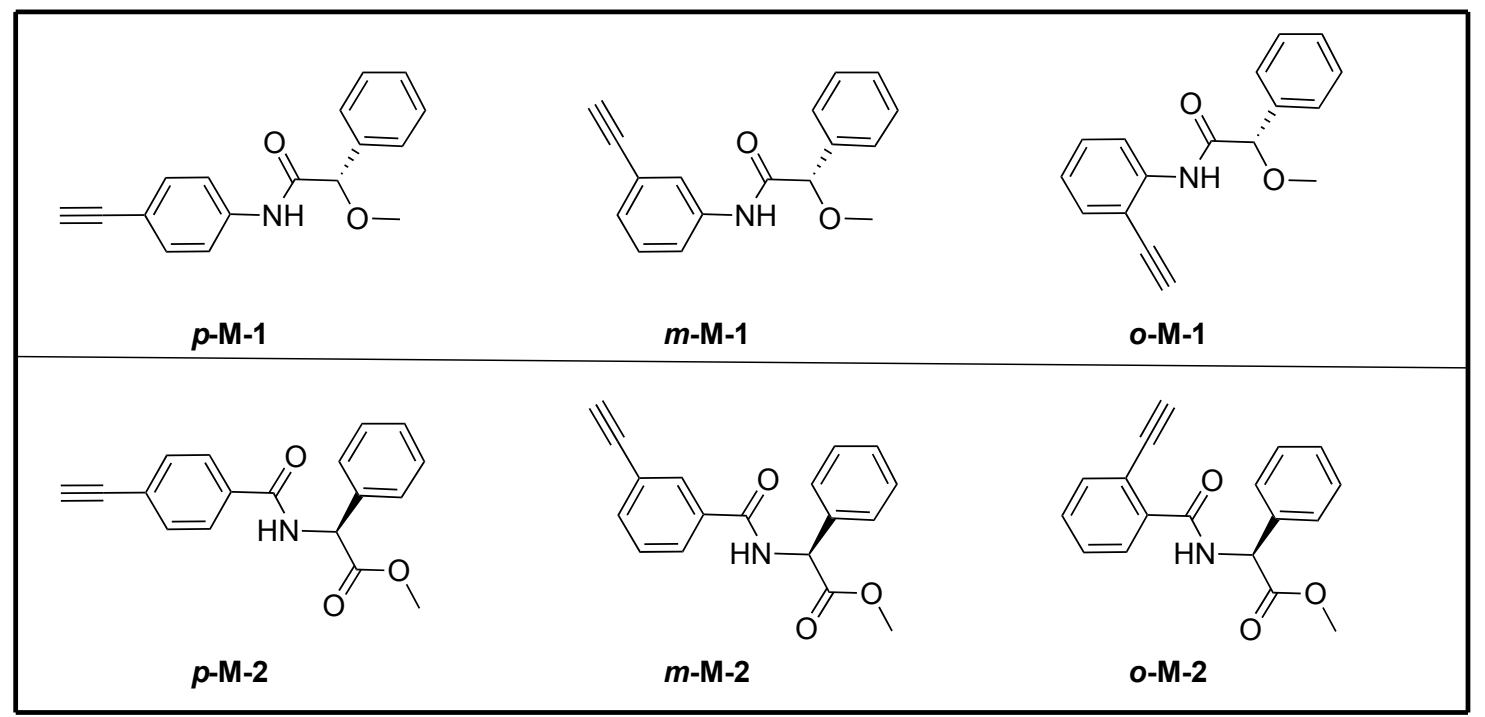

Compounds $p$-M-1, $p$-M-2 and 2-ethynylbenzoic acid were prepared according to previous synthetic procedure (See references S1, S2 and S3 respectively). 
Synthesis of (S)- $N$-(3-ethynylphenyl)-2-methoxy-2-phenylacetamide ( $m$-M-1)

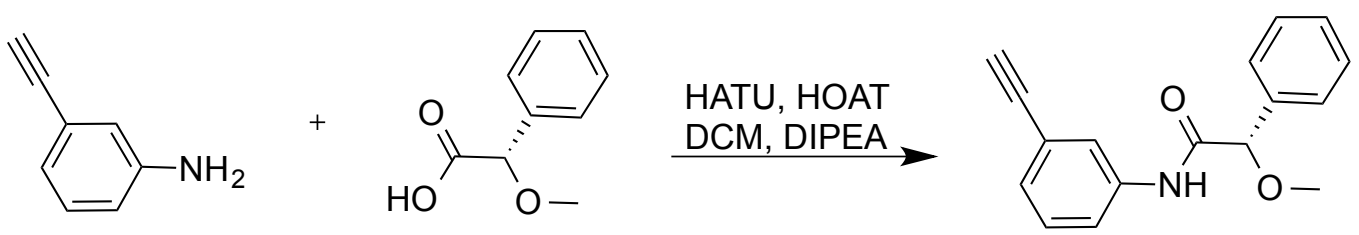

2-(7-Aza-1H-benzotriazole-1-yl)-1,1,3,3-tetramethyluronium (HATU, 2.30 g, 1.4 equiv), 1-hydroxy-7-azabenzotriazole (HOAt, $820 \mathrm{mg}$, 1.4 equiv), (S)- $\alpha$-methoxy- $\alpha$ phenylacetic acid (1 g, 1.4 equiv.) and diisopropyltriethylamine (DIEA, $1 \mathrm{~mL}, 1.4$ equiv) were dissolved in $45 \mathrm{~mL}$ of $\mathrm{CH}_{2} \mathrm{Cl}_{2}$, and the mixture was stirred for $10 \mathrm{~min}$ to activate the acid. Then, 3-ethynylaniline (500mg, $450 \mu \mathrm{L}, 1.0$ equiv) was added and the reaction mixture was stirred overnight. Then, the organic layer was washed with $\mathrm{HCl} 1 \mathrm{M}$, saturated solution of $\mathrm{NaHCO}_{3}$ and brine. The combined organic layers were dried over anhyd $\mathrm{Na}_{2} \mathrm{SO}_{4}$, filtered and the solvent was evaporated at reduced pressure. The crude product was chromatographed on silica gel (70-230 mesh) with hexane/ethyl acetate (7/3) as eluent [1.02 mg m-M1], $90 \%$ yield of pure product. ${ }^{1} \mathrm{H}$ NMR $\left(300 \mathrm{MHz}, \mathrm{CDCl}_{3}\right) \delta(\mathrm{ppm}): 3.04(\mathrm{~s}, 1 \mathrm{H})$, 3.43(s, 3H), 4.73 (s, 1H), 7.20-7.45 (m, 7H), 7.62 (dt, J= 2.3 Hz, J=7.6 Hz, 1H), 7.72 (m, 1H). ${ }^{13} \mathrm{C}$ NMR (62.5 MHz, $\left.\mathrm{CDCl}_{3}\right) \delta(\mathrm{ppm}): 57.6,77.7,83.3,84.1,120.4,123.3$, 127.3, 128.3, 128.9, 129.3, 136.6, 137.6, 168.9 HRMS (ESI) m/z calcd for $\mathrm{C}_{17} \mathrm{H}_{1} 5 \mathrm{NO}_{2}[\mathrm{M}+\mathrm{H}]: 266.1103$, found: 266.1104. $m-\mathrm{M}-\mathbf{1}[\alpha]_{\mathrm{D}}=+75(\mathrm{c}=15 \mathrm{mg} / \mathrm{mL}$, $\left.\mathrm{CHCl}_{3}\right)$. 


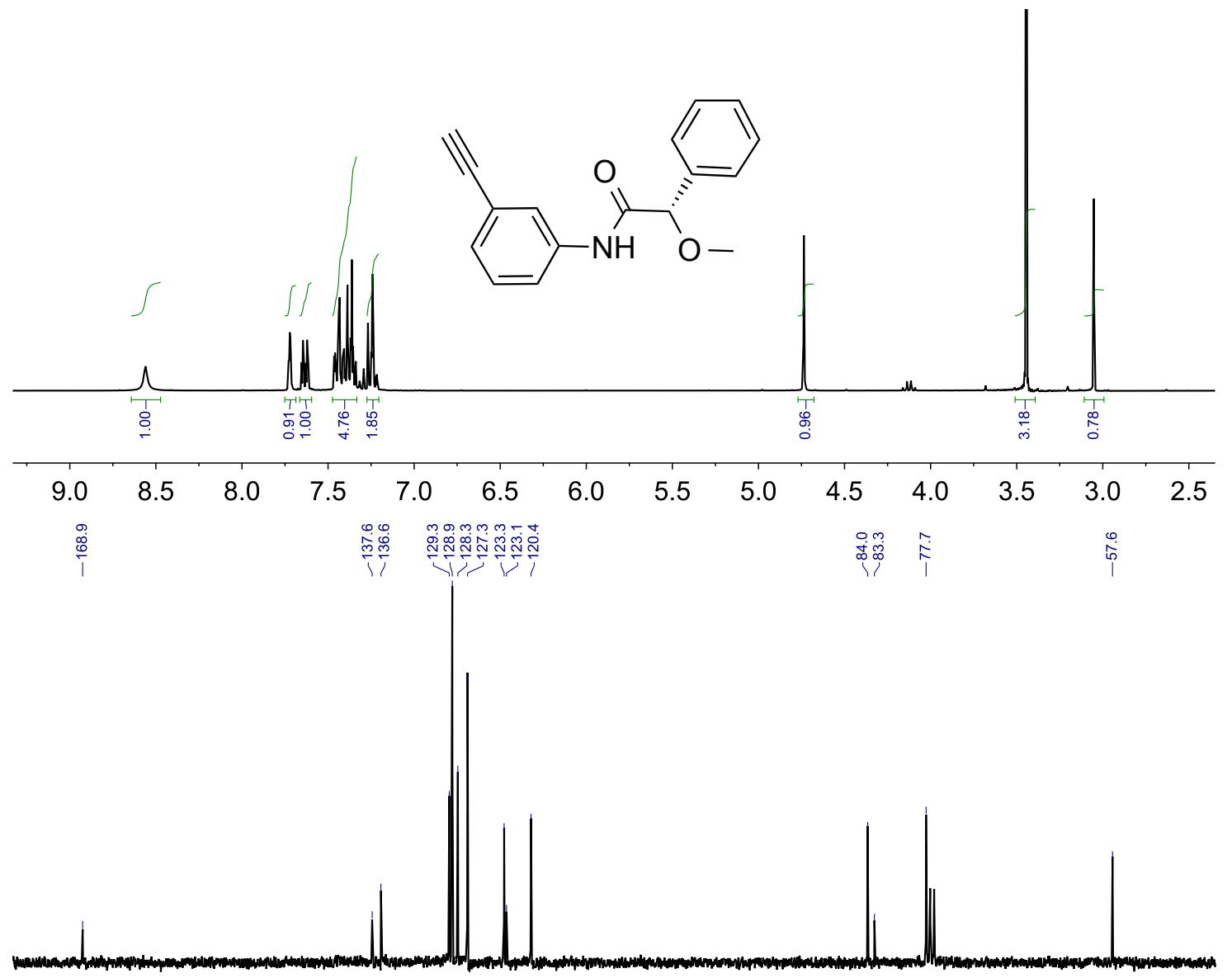

$\begin{array}{lllllllllllll}170 & 160 & 150 & 140 & 130 & 120 & 110 & 100 & 90 & 80 & 70 & 60 & 50\end{array}$

Figure S1. ${ }^{1} \mathrm{H}$ and ${ }^{13} \mathrm{C}$ NMR spectra of $m-\mathrm{M}-1$ 

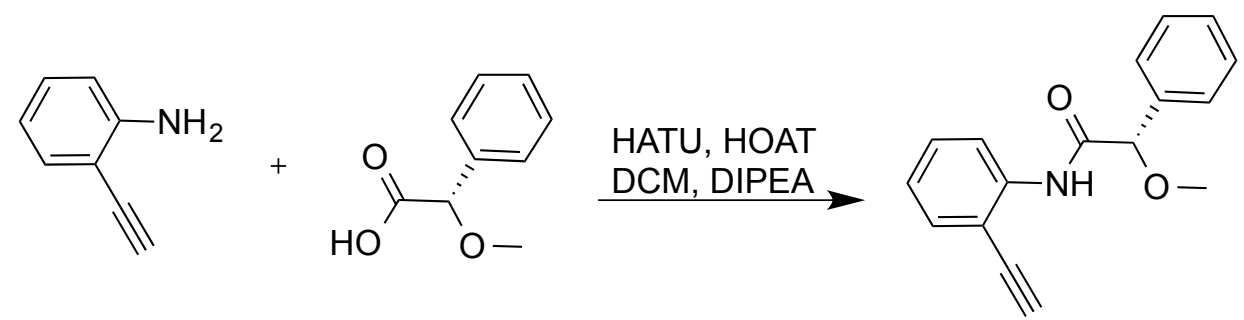

2-(7-Aza-1H-benzotriazole-1-yl)-1,1,3,3-tetramethyluronium

hexafluorophosphate (HATU, 2.30 g, 1.4 equiv), 1-hydroxy-7azabenzotriazole (HOAt, $820 \mathrm{mg}, 1.4$ equiv), $(S)$ - $\alpha$-methoxy- $\alpha$-phenylacetic acid (1 g, 1.4 equiv) and diisopropyltriethylamine (DIEA, $1 \mathrm{~mL}, 1.4$ equiv) were dissolved in $45 \mathrm{~mL}$ of $\mathrm{CH}_{2} \mathrm{Cl}_{2}$, and the mixture was stirred for $10 \mathrm{~min}$ to activate the acid. Then, 2-ethynylaniline (500 mg, $485 \mu \mathrm{L} 1.0$ equiv) was added and the reaction mixture was stirred overnight. Next, the organic layer was washed with $\mathrm{HCl} 1 \mathrm{M}$, saturated solution of $\mathrm{NaHCO}_{3}$ and brine. The combined organic layers were dried over anhyd $\mathrm{Na}_{2} \mathrm{SO}_{4}$, filtered and the solvent was evaporated at reduced pressure. The crude product was chromatographed on silica gel (70-230 mesh) with hexane/ethyl acetate $(7 / 3)$ as eluent [964 mg $o$-M-1], 85\% yield of pure product.

${ }^{1} \mathrm{H}$ NMR (300 MHz, $\left.\mathrm{CHCl}_{3}\right) \delta(\mathrm{ppm}): 3.50(\mathrm{~s}, 3 \mathrm{H}), 3.56(\mathrm{~s}, 1 \mathrm{H}), 4.77(\mathrm{~s}, 1 \mathrm{H}), 7.04(\mathrm{dt}, \mathrm{J}$ $=1.1 \mathrm{~Hz}, \mathrm{~J}=7.6 \mathrm{~Hz}), 7.26-7.51(\mathrm{~m}, 7 \mathrm{H}), 8.40(\mathrm{dd}, \mathrm{J}=1.1 \mathrm{~Hz}, \mathrm{~J}=7.6 \mathrm{~Hz}, 1 \mathrm{H}), 9.47(\mathrm{~s}$, 1H). ${ }^{13} \mathrm{C}$ NMR (62.5 MHz, $\mathrm{CDCl}_{3}$ ) $\delta(\mathrm{ppm}): 57.9,76.9,77.3,79.3,84.5,84.6,111.5$, 119.5, 123.8, 127.3, 128.9, 128.9, 128.9, 130,4. 132.4, 136.9, 139.35, 169.1. HRMS (ESI) $\mathrm{m} / \mathrm{z}$ calcd for $\mathrm{C}_{18} \mathrm{H}_{16} \mathrm{NO}_{3}[\mathrm{M}+\mathrm{H}]:$ 266.1103, found: 266.0107. o-M-1 $[\alpha]_{D}=+200\left(\mathrm{c}=15, \mathrm{CHCl}_{3}\right)$. 

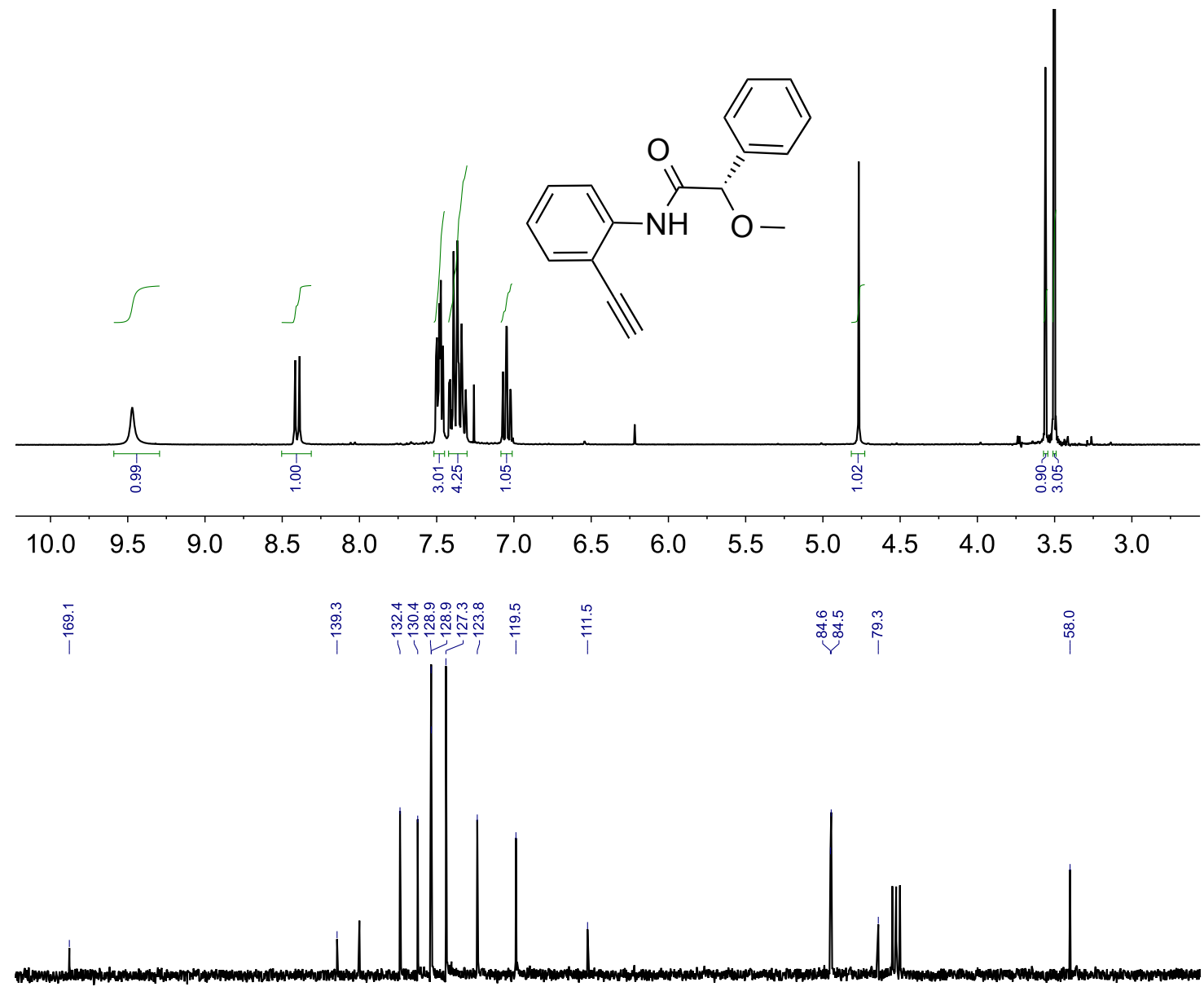

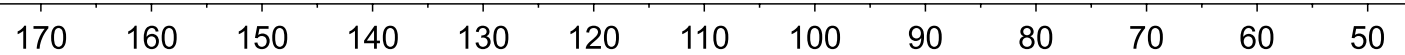

Figure S2. ${ }^{1} \mathrm{H}$ and ${ }^{13} \mathrm{C}$ NMR spectra of $o-\mathrm{M}-1$ 
Synthesis of methyl (S)-2-(3-ethynylbenzamido)-2-phenylacetate ( $m$-M-2)<smiles>C#Cc1cccc(C(=O)O)c1</smiles><smiles>COC(=O)C(N)c1ccccc1</smiles>

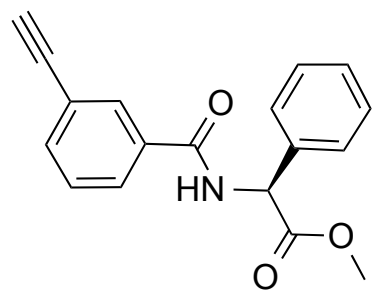

1-Ethyl-3-(3-dimethylaminopropyl)carbodiimide (EDC, 1.35 g, 1.2 equiv), hydroxybenzotriazole (HOBt, 1.4 g, 1.2 equiv), (1.7 g, 1.2 equiv), 3-ethynylbenzoic acid and diisopropyltriethylamine (DIEA, $1 \mathrm{ml}, 2$ equiv) were dissolved in $70 \mathrm{~mL}$ of $\mathrm{CH}_{2} \mathrm{Cl}_{2}$, and the mixture was stirred for $15 \mathrm{~min}$ to activate the acid. Then, $(S)$ phenylglycine methyl ester (1.15 g, 1.0 equiv) was added and the reaction mixture was stirred overnight. The organic layer was washed with $\mathrm{HCl} 1 \mathrm{M}$, saturated solution of $\mathrm{NaHCO}_{3}$ and brine. The combined organic layers were dried over anhyd $\mathrm{Na}_{2} \mathrm{SO}_{4}$, filtered and the solvent was evaporated at reduced pressure. The crude product was chromatographed on silica gel (70-230 mesh) with hexane/ethyl acetate $(7 / 3)$ as eluent [1.32 $\mathrm{g} \mathrm{m}$-M-2], 75\% yield of pure product.

${ }^{1} \mathrm{H}$ NMR (250 MHz, $\left.\mathrm{CHCl}_{3}\right) \delta(\mathrm{ppm}): 3.39$ (s, 1H), 3.40 (s, 3H), 4.75 (s, 1H), 7.34-7.46 (m, 7H), 7.65-7.67 (m, 2H), 9.01 (broad s, $1 \mathrm{H}) .{ }^{13} \mathrm{C}$ NMR (62.5 MHz, $\left.\mathrm{CHCl}_{3}\right) \delta(\mathrm{ppm})$ : 57.7, 78.3, 83.9, 84.6, 128.1, 129.3, 129.4, 133.4, 138.3, 139.5, 170.1. HRMS (ESI) $\mathrm{m} / \mathrm{z}$ calcd for $\mathrm{C}_{18} \mathrm{H}_{15} \mathrm{NO}_{3} \mathrm{Na}[\mathrm{M}+\mathrm{Na}]^{+}$: found: $316.0944 \alpha_{\mathrm{D}}=-71(\mathrm{c}=15 \mathrm{mg} / \mathrm{mL}$, $\left.\mathrm{CHCl}_{3}\right)$. 


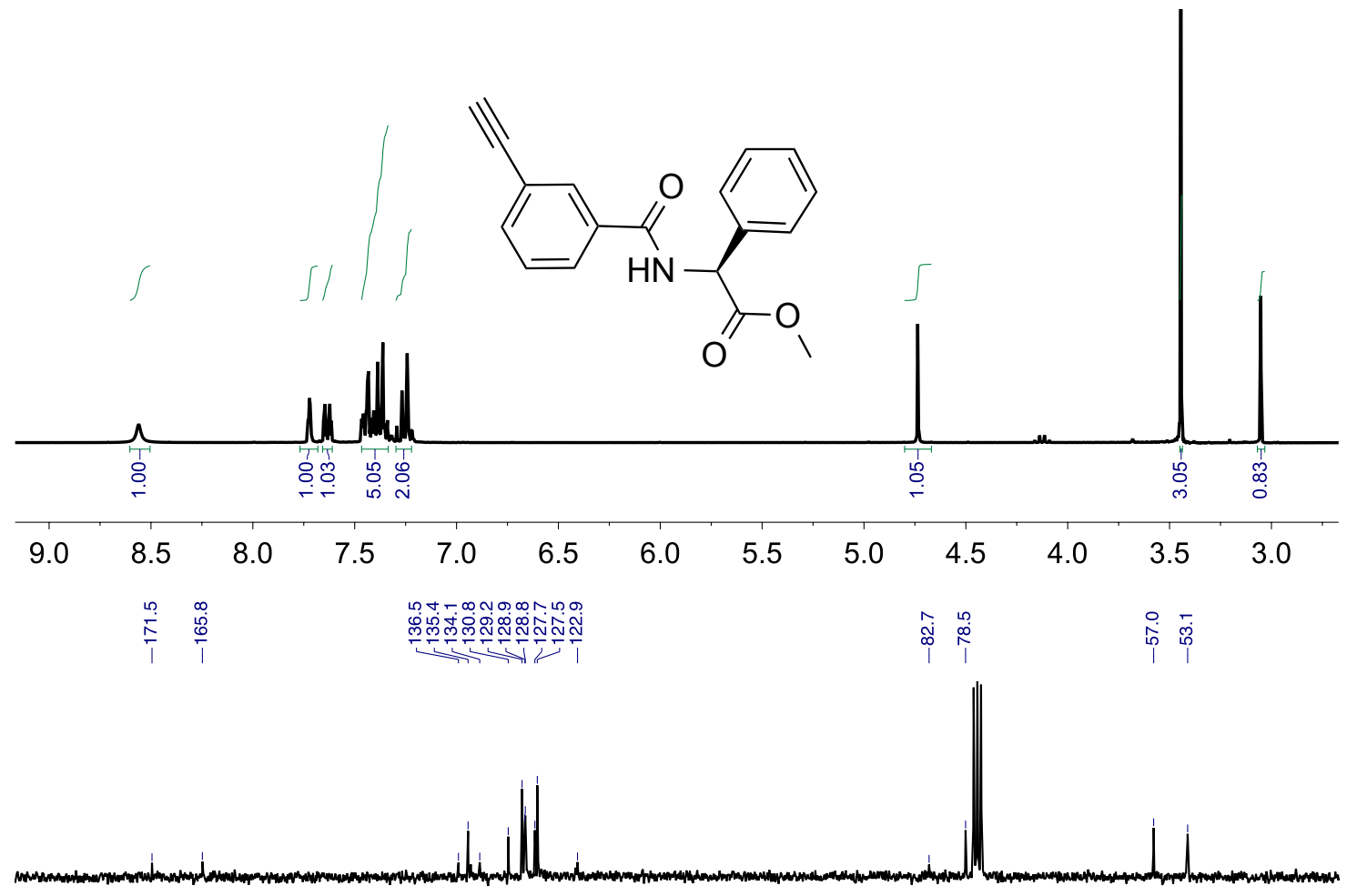

$\begin{array}{lllllllllllllll}180 & 170 & 160 & 150 & 140 & 130 & 120 & 110 & 100 & 90 & 80 & 70 & 60 & 50 & 40\end{array}$

Figure S3. ${ }^{1} \mathrm{H}$ and ${ }^{13} \mathrm{C}$ NMR spectra of $m-\mathrm{M}-2$ 
Synthesis of methyl (S)-2-(2-ethynylbenzamido)-2-phenylacetate $o$-M-2<smiles>C#Cc1ccccc1C(=O)O</smiles><smiles>COC(=O)C(N)c1ccccc1</smiles>
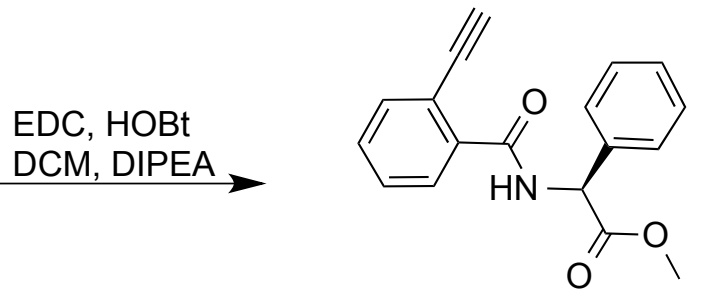

1-Ethyl-3-(3-dimethylaminopropyl)carbodiimide (EDC, 1.35 g, 1.2 equiv), hydroxybenzotriazole (HOBt, $1.4 \mathrm{~g}, 1.2$ equiv), (1.7 g, 1.2 equiv), 2-ethynylbenzoic acid and diisopropyltriethylamine (DIEA, $1 \mathrm{ml}, 2$ equiv) were dissolved in $70 \mathrm{~mL}$ of $\mathrm{CH}_{2} \mathrm{Cl}_{2}$, and the mixture was stirred for $15 \mathrm{~min}$ to activate the acid. Then, (S)phenylglycine methyl ester (1.15 g, 1.0 equiv) was added and the reaction mixture was stirred overnight. The organic layer was washed with $\mathrm{HCl} 1 \mathrm{M}$, saturated solution of $\mathrm{NaHCO}_{3}$ and brine. The combined organic layers were dried over anhyd $\mathrm{Na}_{2} \mathrm{SO}_{4}$, filtered and the solvent was evaporated at reduced pressure. The crude product was chromatographed on silica gel (70-230 mesh) with hexane/ethyl acetate $(7 / 3)$ as eluent [1.34 $\mathrm{mg} o$-M-2], 75\% of pure product.

${ }^{1} \mathrm{H}$ NMR $\left(300 \mathrm{MHz} \mathrm{CHCl}_{3}\right) \delta(\mathrm{ppm}): 3.54(\mathrm{~s}, 1 \mathrm{H}), 3.74(\mathrm{~s}, 3 \mathrm{H}), 5.79(\mathrm{~d}, J=6.6 \mathrm{~Hz}, 1 \mathrm{H})$, 7.23-7.48 (m, 8H), 7.95-8.10 (m, 1H), $8.59(\mathrm{~d}, J=6.7 \mathrm{~Hz}, 1 \mathrm{H}) \cdot{ }^{13} \mathrm{C}$ NMR $(62.5 \mathrm{MHz}$, $\left.\mathrm{CHCl}_{3}\right) \delta(\mathrm{ppm}):$ 53.1, 82.2, 84.7, 127.6, 128.7, 129.1, 129.6, 130.5, 131.1, 134.4, 135.3, 136.7, 165.2, 171.5 HRMS (ESI) m/z calcd for $\mathrm{C}_{17} \mathrm{H}_{15} \mathrm{NO}_{2}[\mathrm{M}+\mathrm{H}]^{+}:$266.1103, found: $266.1102 \alpha_{\mathrm{D}}=-75$ (c=15 $\mathrm{mg} / \mathrm{mL}, \mathrm{CHCl}_{3}$ ). 


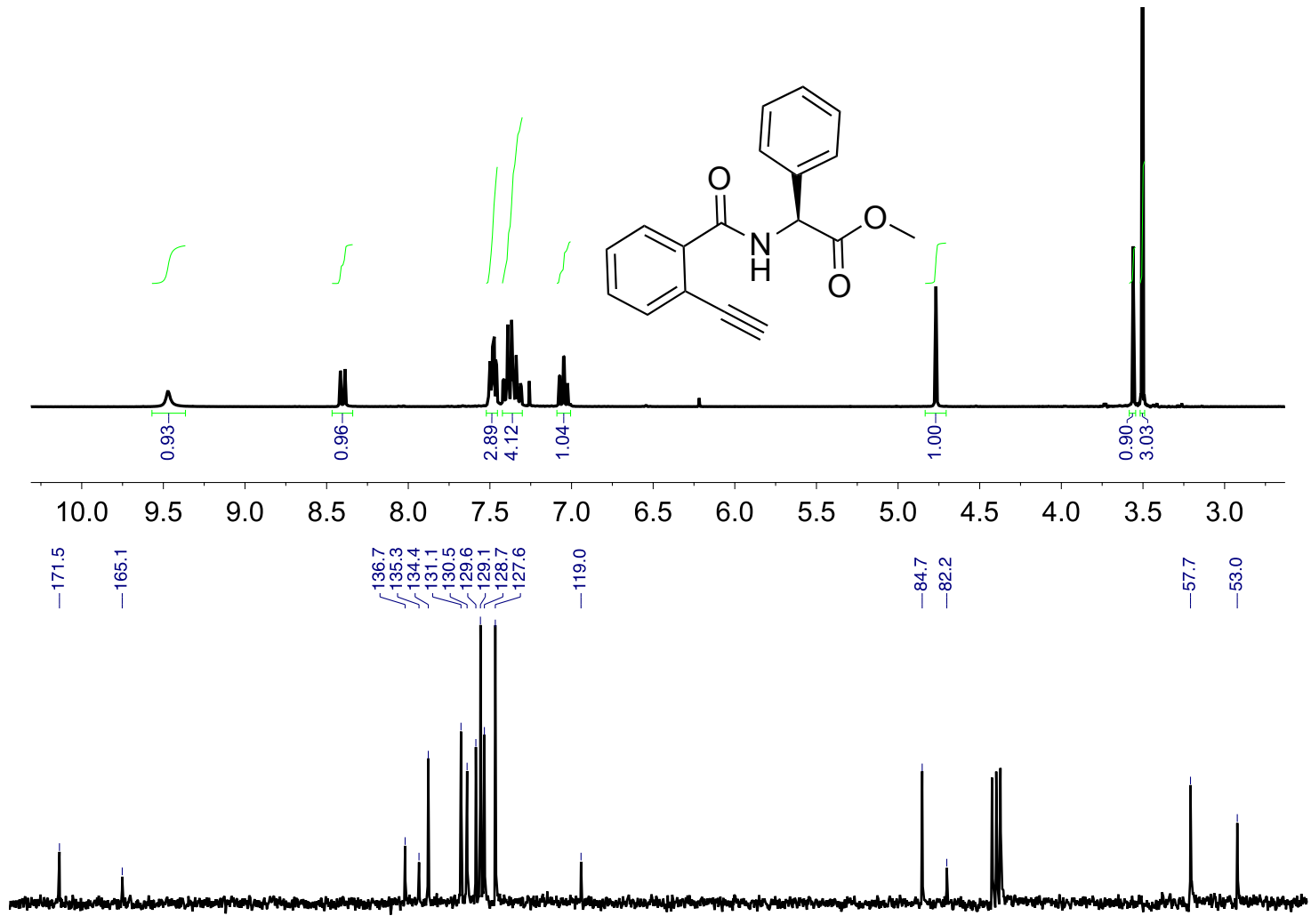

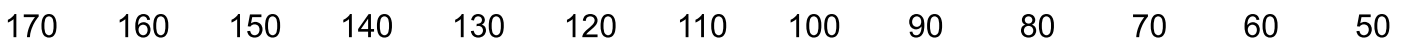

Figure S4. ${ }^{1} \mathrm{H}$ and ${ }^{13} \mathrm{C}$ NMR spectra of $o-\mathrm{M}-2$ 


\section{Studies of Monomers}

a)

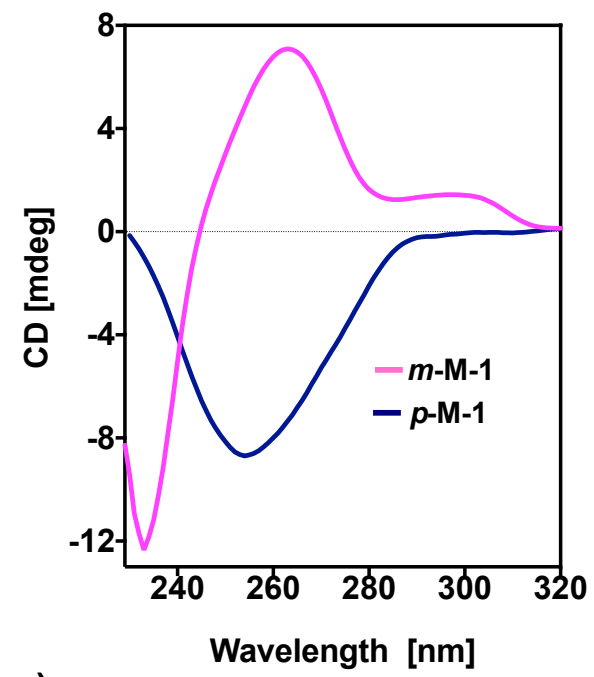

c)

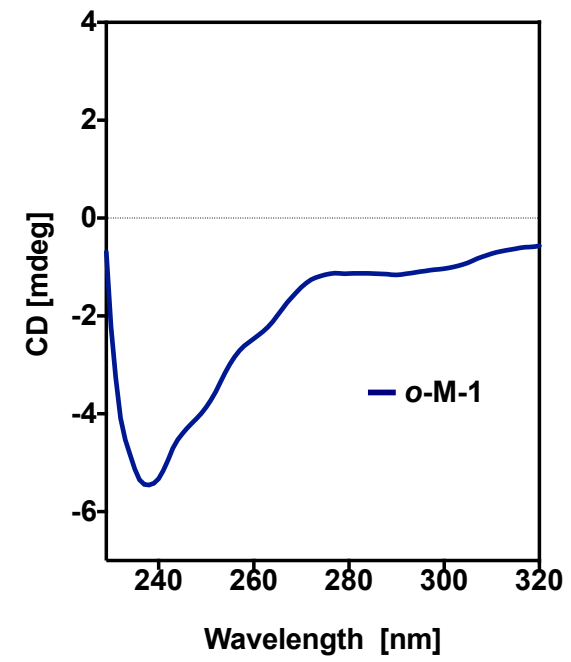

b)

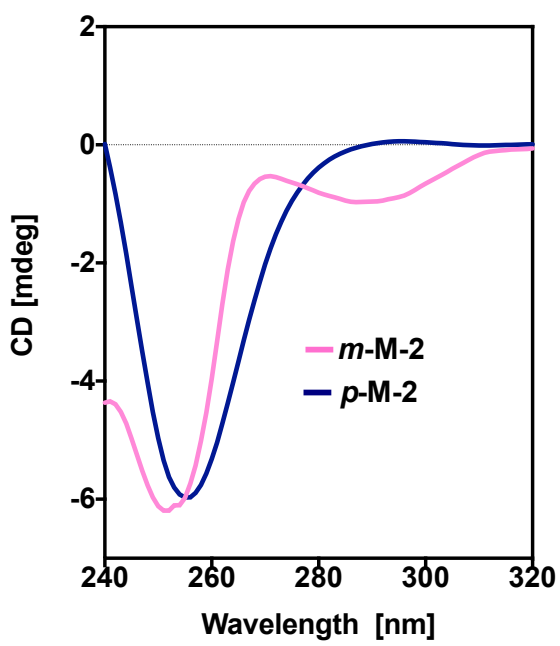

c)

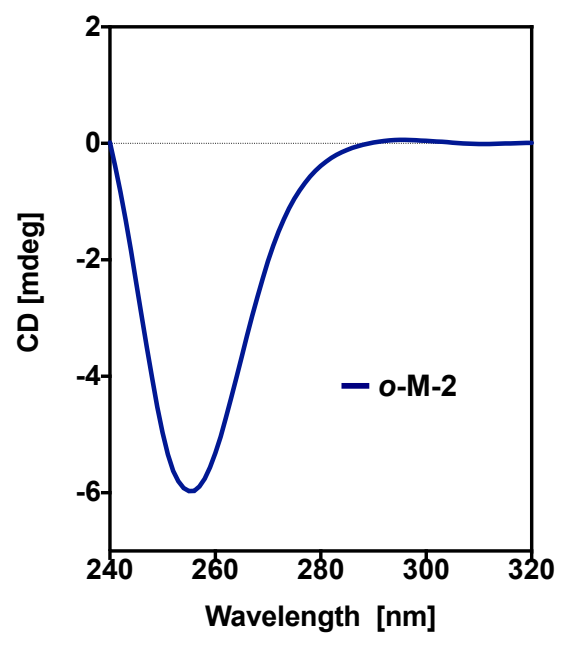

Figure S5. a) Overlay of the CD spectra of $m-\mathrm{M}-1$ and $p$-M-1. b) Overlay of the CD spectra of $m-\mathrm{M}-2$ and $p-\mathrm{M}-2$ monomers. c) CD spectrum of $o-\mathrm{M}-1$. d) CD spectrum of $o-\mathrm{M}-2$. All CD spectra were recorded in THF at $0.2 \mathrm{mg} / \mathrm{mL}$.

When the CD spectra of para- and meta-substituted monomers are compared, clear differences can be observed related to the bands between 250-300 nm (Figure S5). In the case of $m-\mathrm{M}-1$, the band between $250-300 \mathrm{~nm}$ is positive (negative in $p$-M-1), and opposite to the negative Cotton effect observed at $230 \mathrm{~nm}$ related to the ap conformation of carbonyl and methoxy groups (Figure S5a). On the contrary, in the case of $m-\mathrm{M}-2$, the analogous band is negative and has the same Cotton effect sign as the band at $250 \mathrm{~nm}$ related to the ap conformation of both carbonyl groups (Figure S5b). The different signs of the Cotton effect at 250-300 $\mathrm{nm}$ in both 
monomers $m-\mathrm{M}-1$ and $m-\mathrm{M}-2$ can be ascribed to the different orientations of the carbonyl groups related to the alkyne. While in monomer $m-\mathrm{M}-\mathbf{1}$, the carbonyl group is oriented towards the aromatic $\mathrm{H}$ in ortho position to the alkyne and the amide group (see X-ray of $m-\mathrm{M}-1$, Figure $5 \mathrm{c}$ in manuscript), in the case of monomer $m-\mathrm{M}-2$, the carbonyl group is oriented towards the aromatic proton in para position to the alkyne (see X-ray of $m-\mathrm{M}-2$, Figure $5 \mathrm{~d}$ in manuscript). These facts suggest that in these chiral meta-substituted phenylacetylenes, the amide group and the pendant moiety adopt a specific conformation both in solid and solution states, which eventually will determine the helical structure of the polymer.

In the case of o-M-1 and o-M-2, the CD shows the signature of the ap conformation (Figures S5c and S5d), also found in their X-ray structures (Figures 10b and 10c in manuscript), and in the other monomers described in this work. These studies suggest that the amide bonds in both cases present a similar conformation where the carbonyl group points towards its ortho-aromatic hydrogen. 


\section{Synthesis of Polymers}

The polymers were synthesized in a flask (sealed ampoule) that was dried under vacuum and flushed with Ar for three times before the monomers were added as a solid. Then, the flask was evacuated on a vacuum line and flushed with dry $\mathrm{Ar}$ (three times). Dry THF was added via a syringe; then a solution of rhodium norbornadiene chloride dimer $[\mathrm{Rh}(\mathrm{nbd}) \mathrm{Cl}]_{2}$ in $\mathrm{THF}$ was added at $30{ }^{\circ} \mathrm{C}$. The reaction mixture was stirred at $30{ }^{\circ} \mathrm{C}$ for $2 \mathrm{~h}$. Next, the resulting polymers were diluted in THF and precipitated in a large amount of $\mathrm{MeOH}$, centrifuged (twice) and reprecipitated in hexane and centrifuged again.

$\begin{array}{cccccc}\text { Monomer } & \text { Mass }(\mathbf{m g}) & \text { THF }(\boldsymbol{\mu L}) & \text { Et3N }(\boldsymbol{\mu L}) & \text { Catalyst }(\mathbf{m g}) & \text { Yield (mg) } \\ \boldsymbol{p} \text {-M-1 } & 100 & 1000 & 5 & 2 & 96 \\ \boldsymbol{m} \text {-M-1 } & 100 & 1000 & 5 & 2 & 95 \\ \boldsymbol{o} \text {-M-1 } & 100 & 1000 & 5 & 2 & 89 \\ \boldsymbol{p} \text {-M-2 } & 100 & 1000 & 5 & 2 & 98 \\ \boldsymbol{m} \text {-M-2 } & 100 & 1000 & 5 & 2 & 97 \\ \boldsymbol{o}-\mathbf{M}-\mathbf{2} & 100 & 1000 & 5 & 2 & 0^{*}\end{array}$

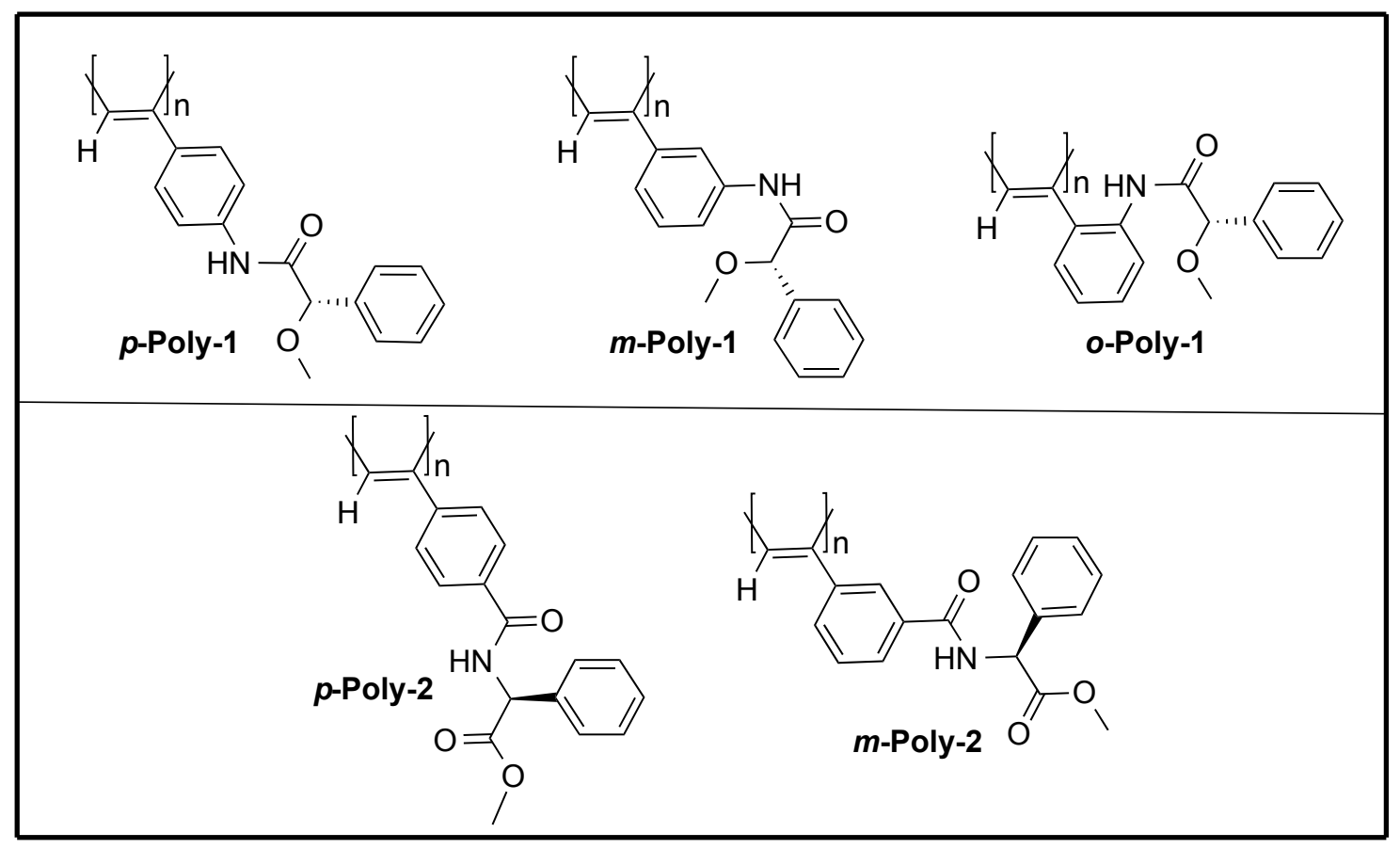

The cis stereoregularity of the polymers was determined by ${ }^{1} \mathrm{H}$ NMR spectroscopy, where the vinyl proton resonates at $5.8 \mathrm{ppm}$, and Raman resonances (Figures S6, S7 and S8). The peak at $1570-1550 \mathrm{~cm}^{-1}$ is assigned to $\mathrm{C}=\mathrm{C}$ bond stretching in the cis polyacetylene and overlaps with that of the phenyl ring. The peak at 1350-1340 
$\mathrm{cm}^{-1}$ is assigned to the cis $\mathrm{C}-\mathrm{C}$ bond coupled with the single bond connecting the main chain and the phenyl ring. The peak at $1010-970 \mathrm{~cm}^{-1}$ is assigned to the $\mathrm{C}-\mathrm{H}$ bond deformation of the cis form.

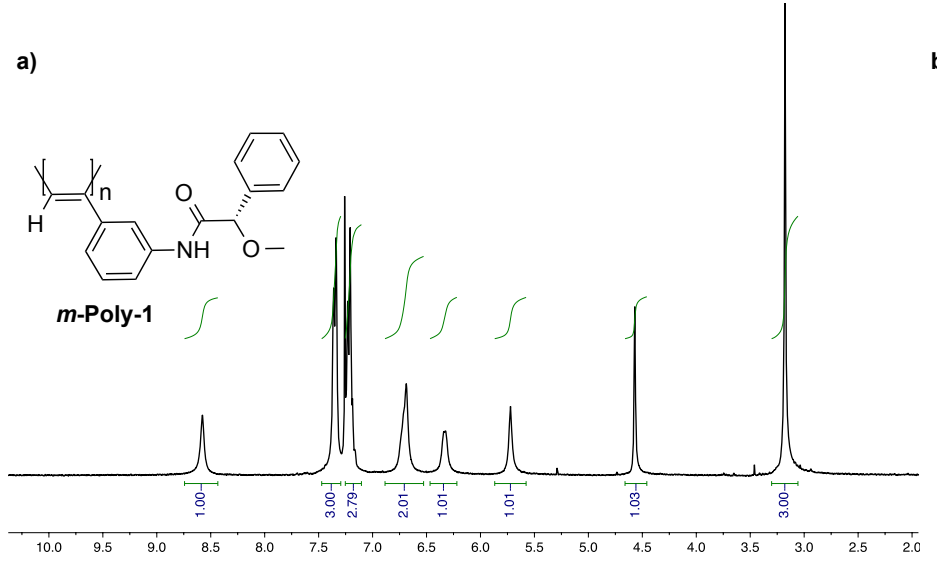

b)

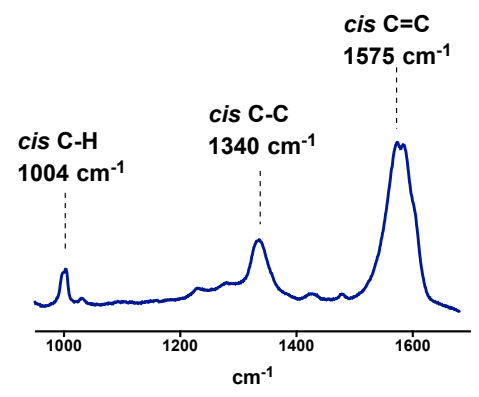

Figure S6. ${ }^{1} \mathrm{H}$ NMR and Raman spectra of $m$-poly-1.

a)

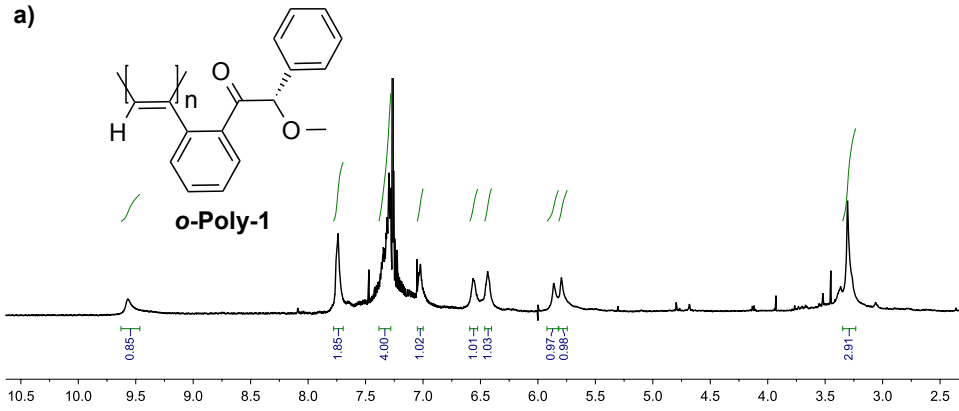

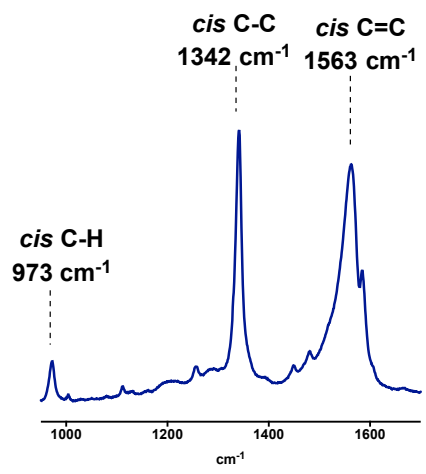

Figure S7. ${ }^{1} \mathrm{H}$ NMR and Raman spectra of $o$-poly-1. 
a)

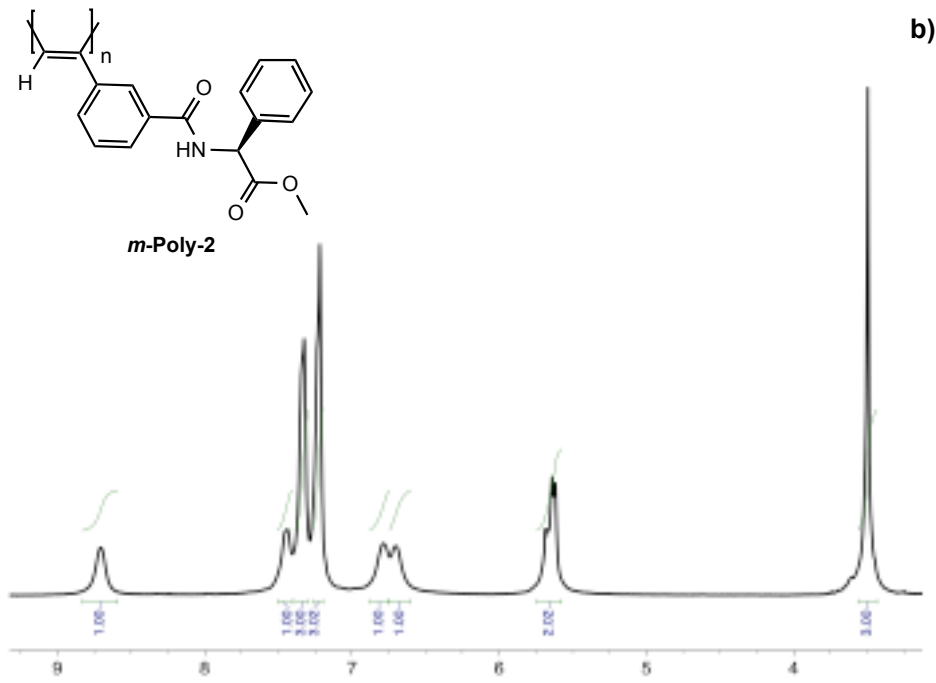

b)

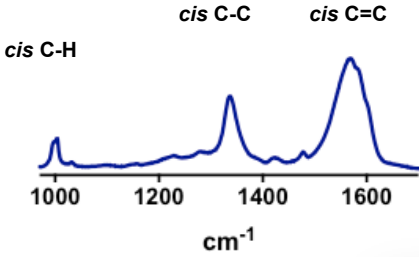

Figure S8. ${ }^{1} \mathrm{H}$ NMR and Raman spectra of $m$-poly-2. 


\section{GPC studies}

For GPC data of $p$-poly-1 and $p$-poly-2 see references S1 and S2 respectively. For GPC data of the new polymers see the table below.

$\begin{array}{cccccc}\text { Polymer } & \text { Mn } & \text { Mw } & \text { Mp } & \text { Mz } & \text { PDI } \\ m \text {-poly-1 } & 64843 & 151505 & 138784 & 328120 & 2.33 \\ o \text {-poly-1 } & 7339 & 10750 & 10731 & 14105 & 1.40 \\ m \text {-poly-2 } & 25469 & 109758 & 83772 & 341225 & 4.31\end{array}$




\section{Circular Dichroism and Ultraviolet Studies}

For detailed CD/UV studies of $p$-poly-1 and $p$-poly-2, see references $\mathbf{S 1}$ and $\mathbf{S 2}$.

For those related to $m$-poly-1, $m$-poly-2 and $o$-poly-1, see the manuscript. 


\section{Thermal Studies}

DSC Studies were carried out in order to determine de geometry of the polymer backbone. As a general protocol a polymer sample was kept in a aluminum pan and heated from $40^{\circ} \mathrm{C}$ to $350^{\circ} \mathrm{C}$ with a heating rate of $10^{\circ} \mathrm{C} / \mathrm{min}$ (Figure $\mathrm{S} 9$ ).

a)
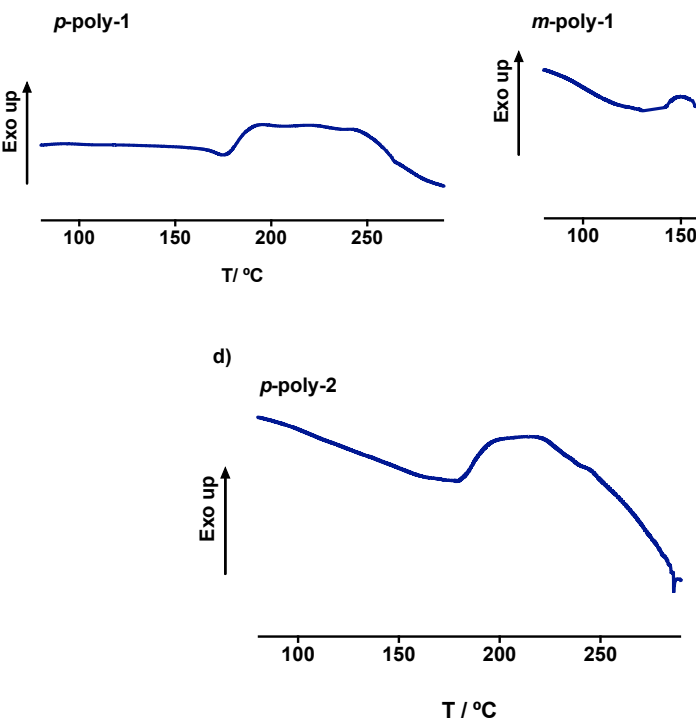

b)

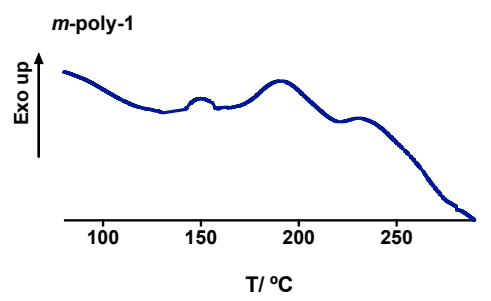

e)

m-poly-2

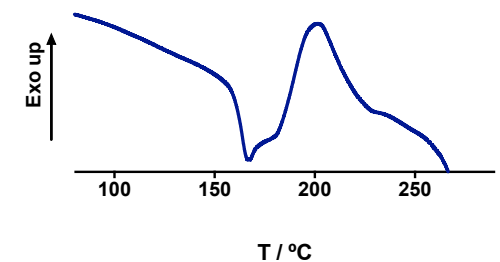

Figure S9. DSC thermograms of a) $p$-poly-1, b) $m$-poly-1, c) $o$-poly-1, d) $p$-poly-2, e) $m$-poly-2.

DSC studies for $m$-poly-1 showed a thermogram typical for a cis-transoidal backbone, where two exothermal peaks corresponding to the $c-t$ to $c-c$ and the $c-c$ to $t-t$ were observed. The cis-transoidal signature overlaps with the expected for the cis-cisoidal one, and as a result it is not possible to observe both polyene conformations from this experiment.

TGA Studies were carried out in order to determine the thermal stability of the polymers. As a general protocol a polymer sample was kept in a platinum pan and heated from $40^{\circ} \mathrm{C}$ to $800^{\circ} \mathrm{C}$ with a heating rate of $10^{\circ} \mathrm{C} / \mathrm{min}$ (Figure S10). 

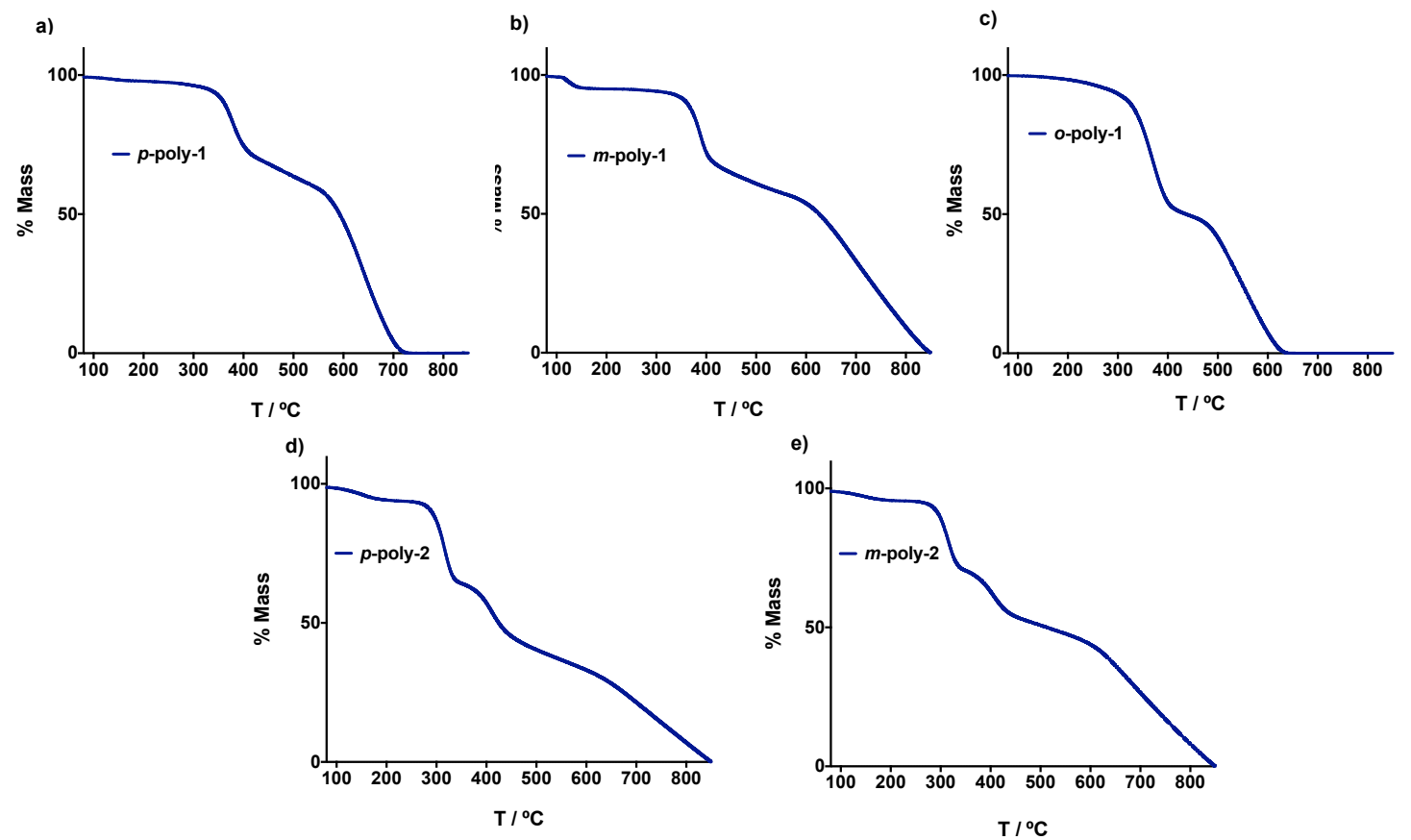

Figure S10. TGA thermograms of a) $p$-poly-1, b) $m$-poly-1, c) $o$-poly-1, d) $p$-poly-2, e) $m$-poly-2. 


\section{AFM studies}

Sample preparations. Langmuir-Schaefer monolayers of $m$-poly-1, $p$-poly-2 and $m$-poly-2 were prepared according to the previously reported method (reference S5). In the case of $o$-poly-1, a dilute chloroform solution of the polymer $(0.01$ $\mathrm{mg} / \mathrm{mL}$ ) was spin coated onto a HOPG substrate and kept under solvent vapors overnight.

\section{AFM Studies of $m$-poly-1}
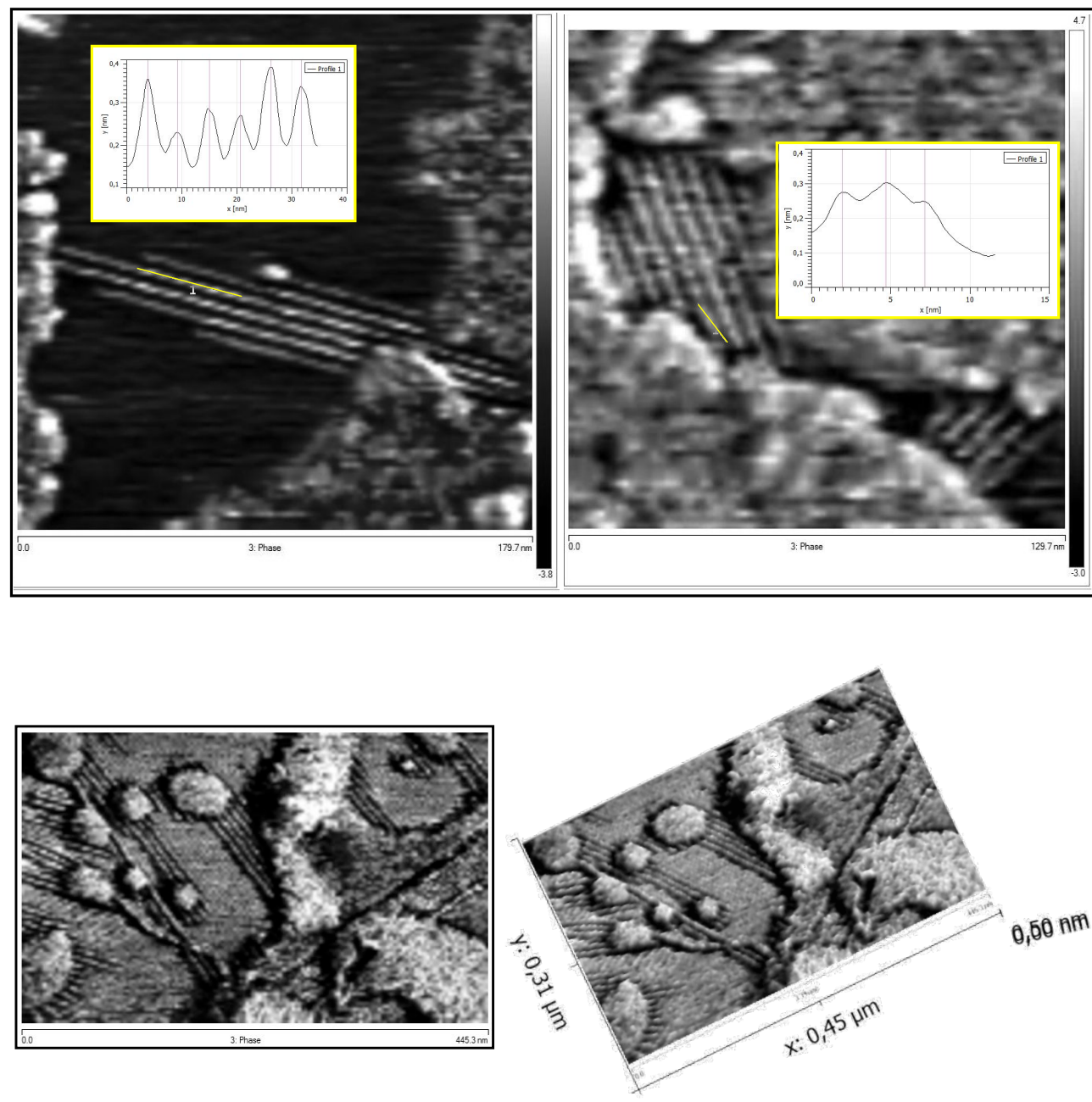

Figure S11. AFM images showing stretched and compressed helical structures for $m$-poly-2. The coexistence of both helical structures (stretched left-handed and compressed right-handed) is shown in a large-scale image and its corresponding 3D projection. 
AFM Studies of $o$-poly-1
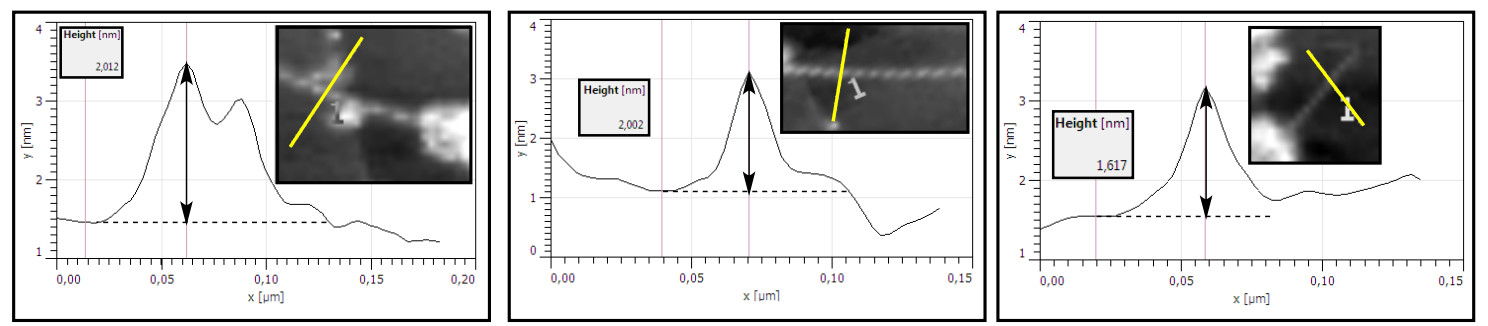

Figure S12. Height profiles of the corresponding superhelices generated by $o$-poly1 (inset picture).

\section{SEM studies of $o$-poly-1}

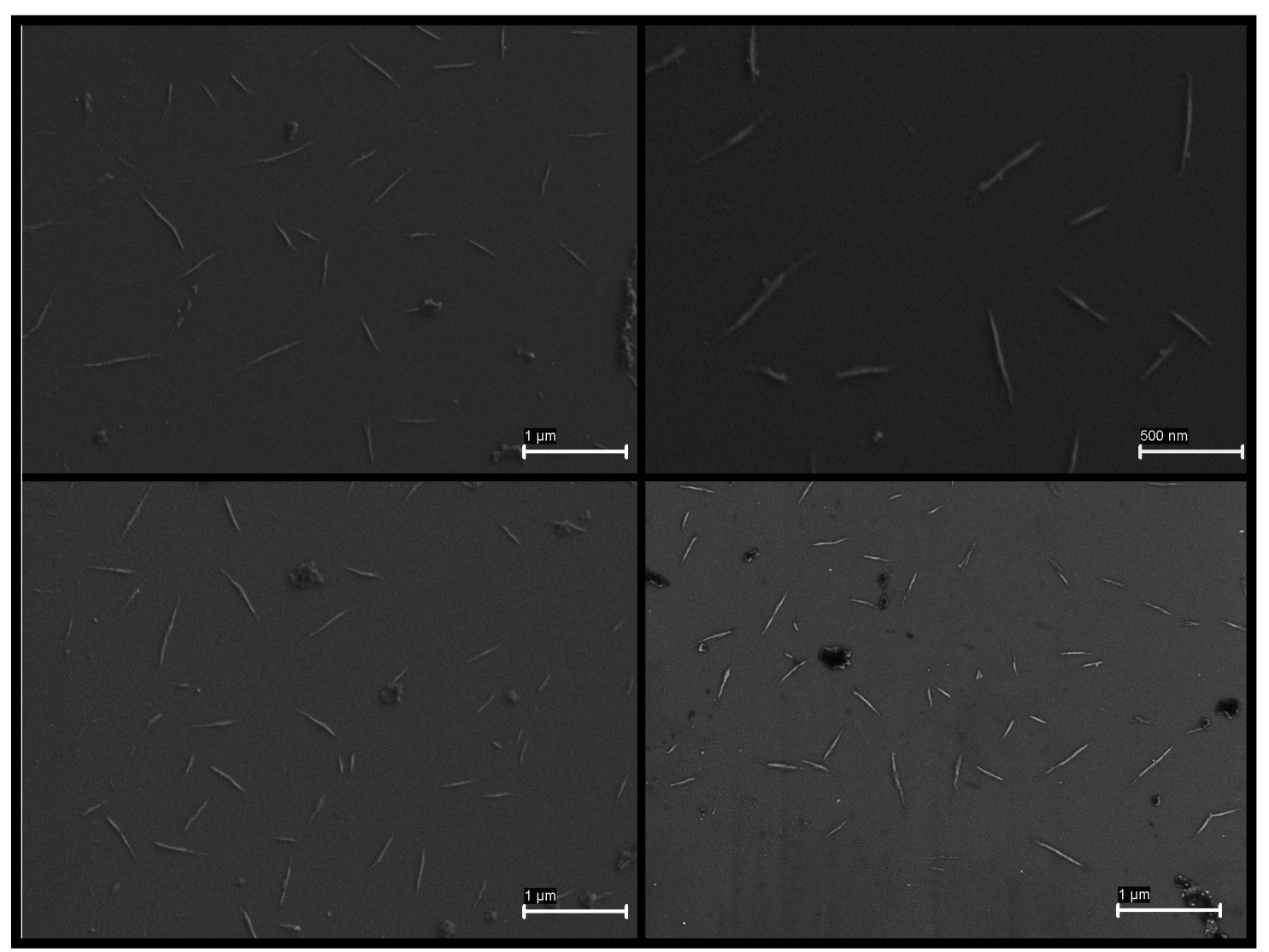

Figure S13. SEM images of fiber-like aggregates generated by $o$-poly-1. 


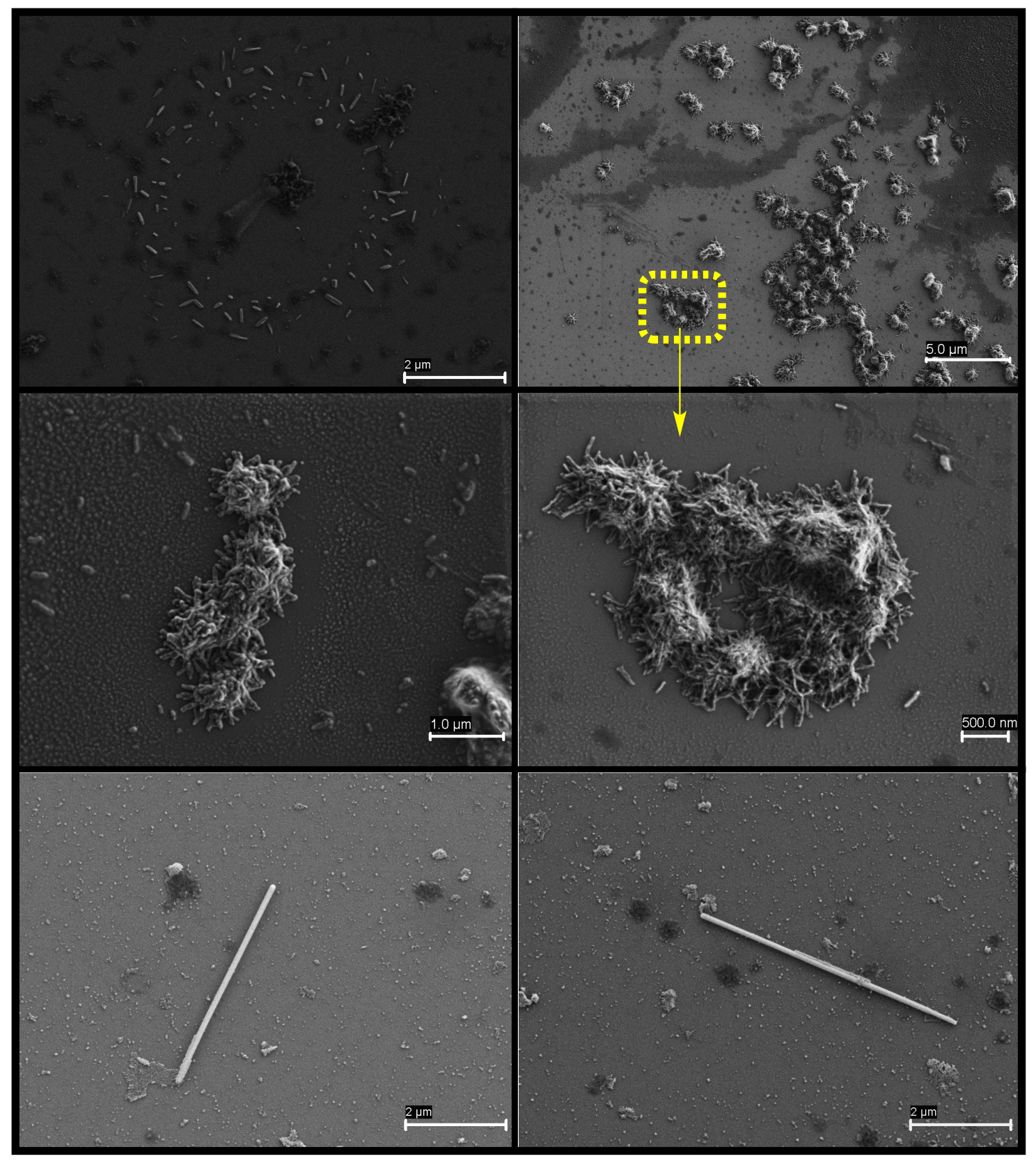

Figure S14. SEM images of rod-like aggregates generated by $o$-poly-1. 


\section{AFM Studies of $m$-poly-2}
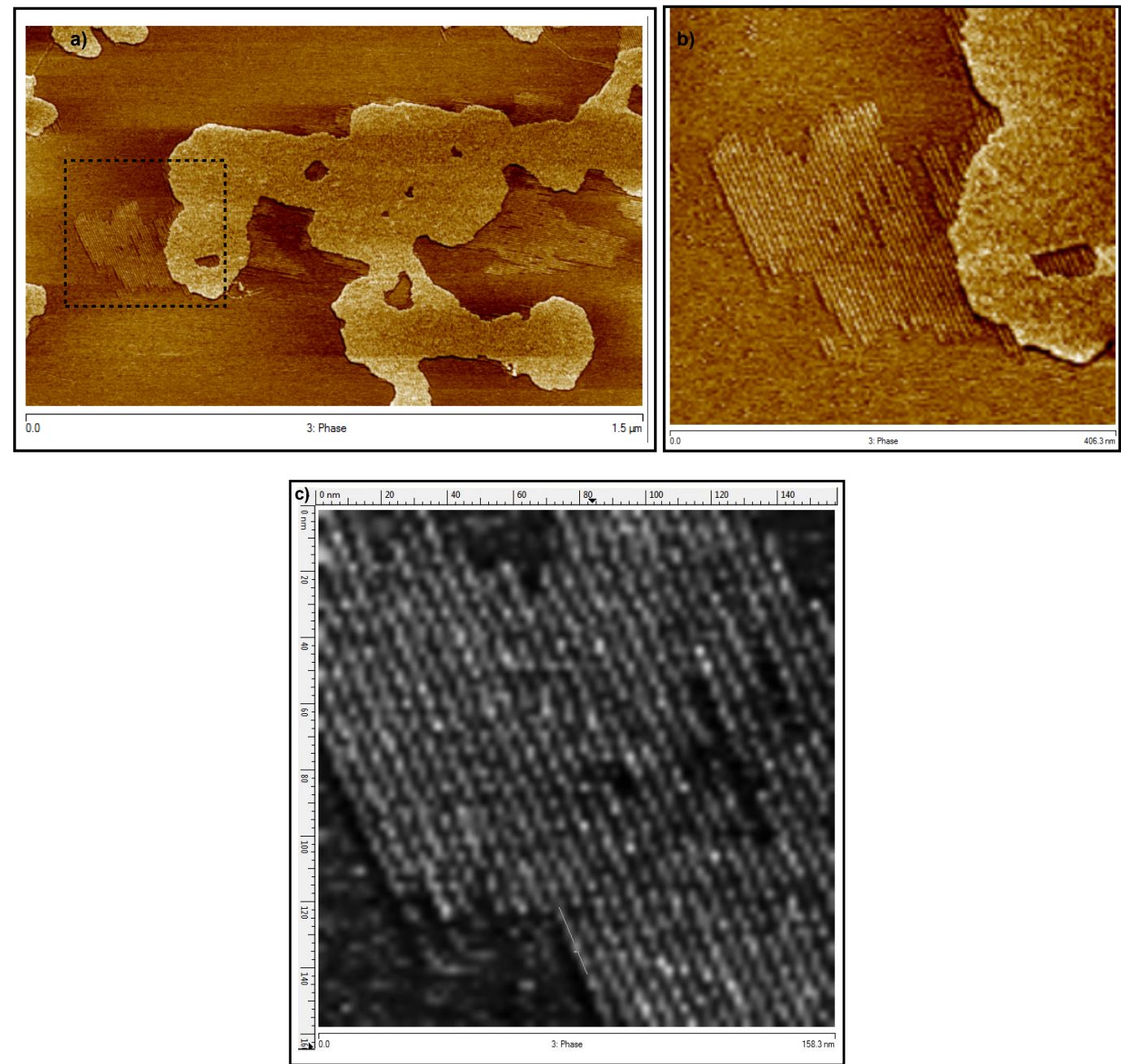

Figure S15. AFM Images of the stretched structure of $m$-poly-2. a) Large scale AFM image of $m$-poly-2 monolayers. b) Magnification of the highlighted area. c) Magnification of b) showing the helical chains in detail.

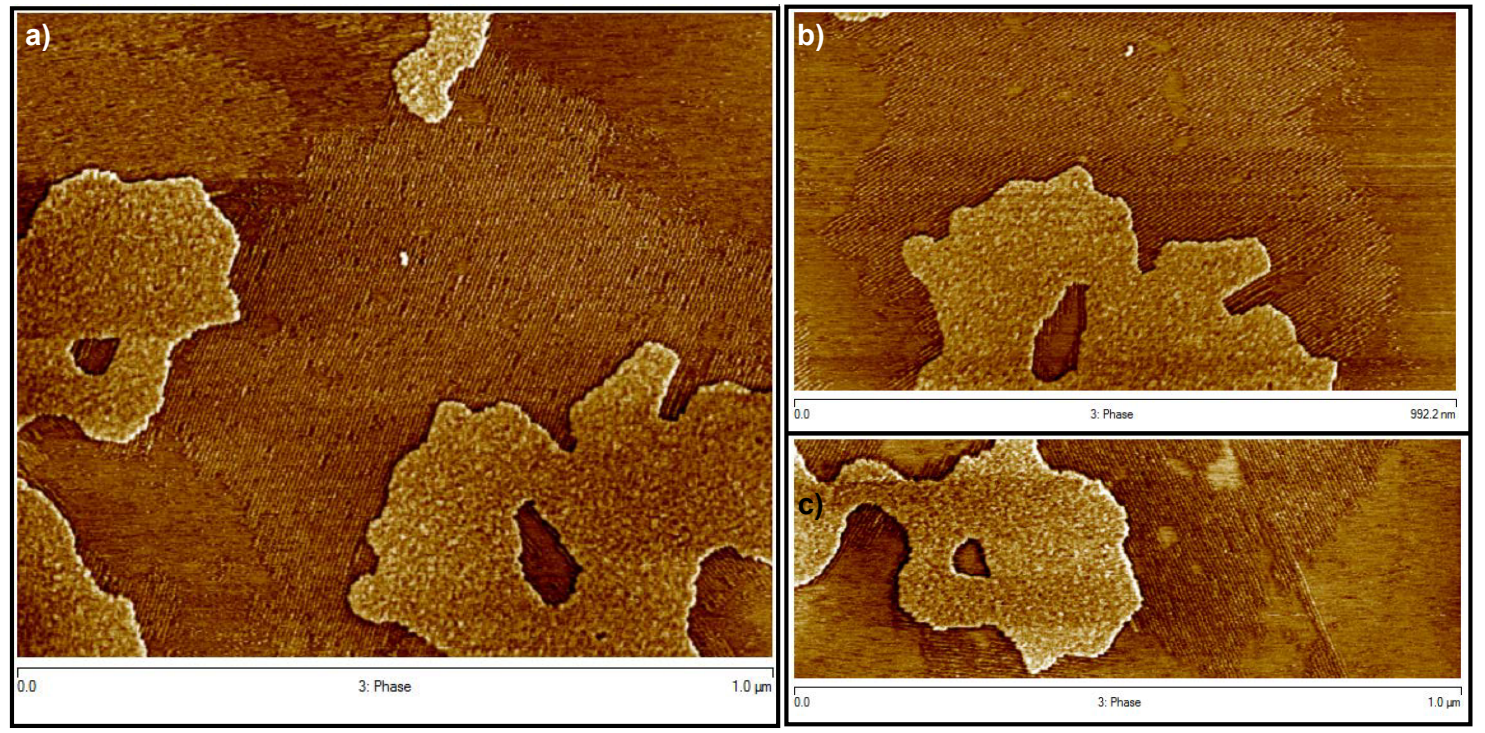




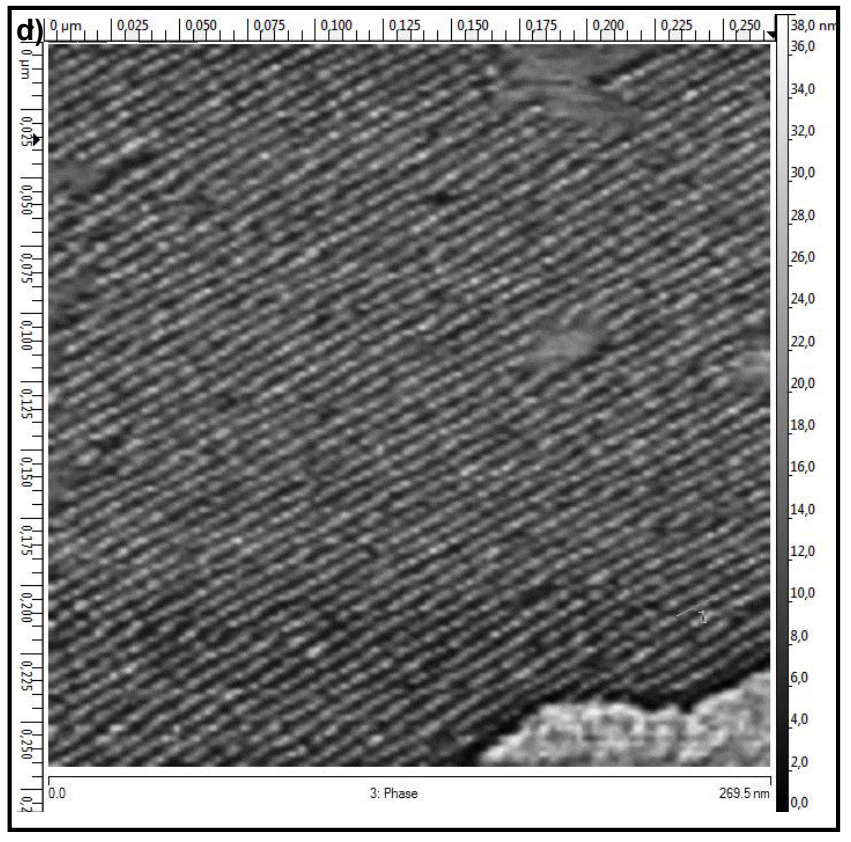

Figure S16. AFM images of the compressed structure of $m$-poly-2. Large scale AFM image of $m$-poly-2 monolayers a), b) and c). d) Magnification showing the helical chains in detail. 


\section{Response of the Polymers to External Stimuli: Solvents and Metal}

\section{Cations}

The different responses of the para polymers (i.e., $p$-poly-1 and $p$-poly-2) to a range of external stimuli -i.e., solvents with different donor/acceptor/polarity characteristics and mono- and divalent metal cations- have already been published (references S1 and S2).

The meta polymers, in addition to the responses already mentioned in the manuscript (e.g., to temperature variation, to solvents), were tested with mono(e.g., $\mathrm{Li}^{+}, \mathrm{Na}^{+}, \mathrm{Ag}^{+}$) and divalent (e.g., $\mathrm{Ca}^{2+}, \mathrm{Ba}^{2+}, \mathrm{Co}^{2+}, \mathrm{Ni}^{2+}$ ) metal cations. In these experiments, the meta polymers showed that they do not undergo the helical inversion, helical selection and chiral amplification phenomena observed with their para counterparts (references S1 and S2) (Figures S17 and S18).

Finally, $o$-poly-1 virtually did not show any noticeable response when submitted to analogous experiments, thus confirming its slightly dynamic nature (Figure 19).
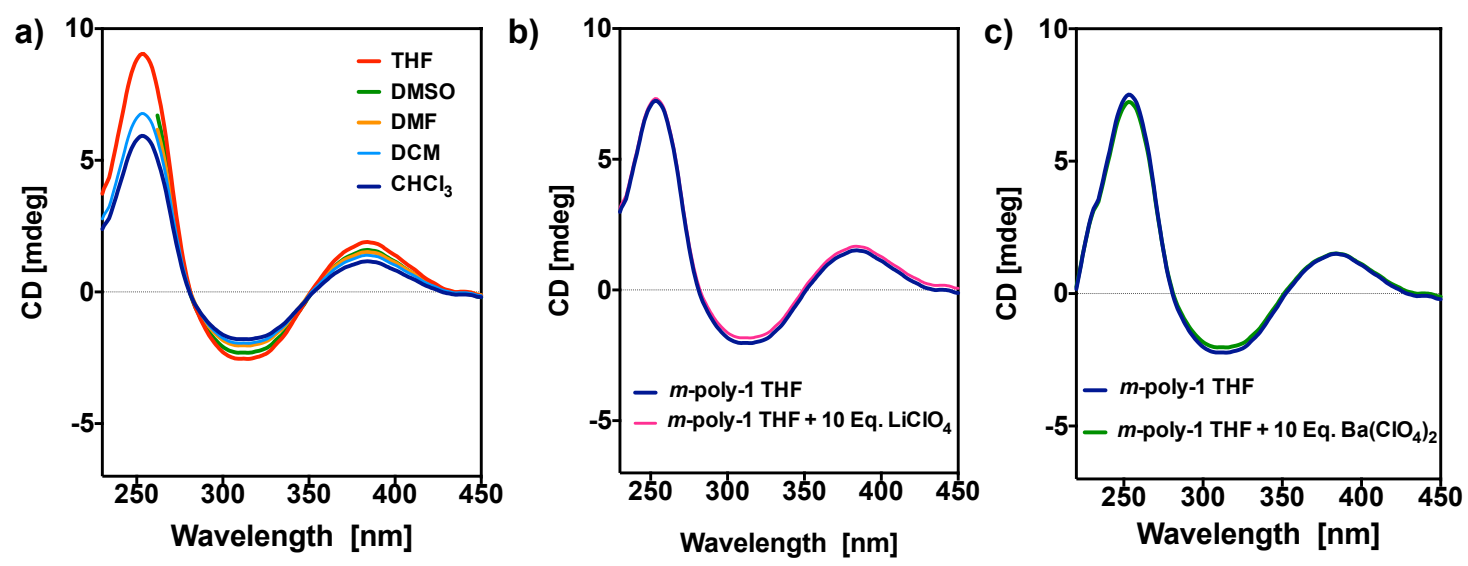

Figure S17. a) CD spectra of $m$-poly-1 in different solvents. b) CD spectra of $m$ poly-1 in THF before and after the addition of 10 equiv of $\mathrm{LiClO}_{4}$. c) $\mathrm{CD}$ spectra of $m$-poly-1 in THF before and after the addition of 10 equiv of $\mathrm{Ba}\left(\mathrm{ClO}_{4}\right)_{2}$. 

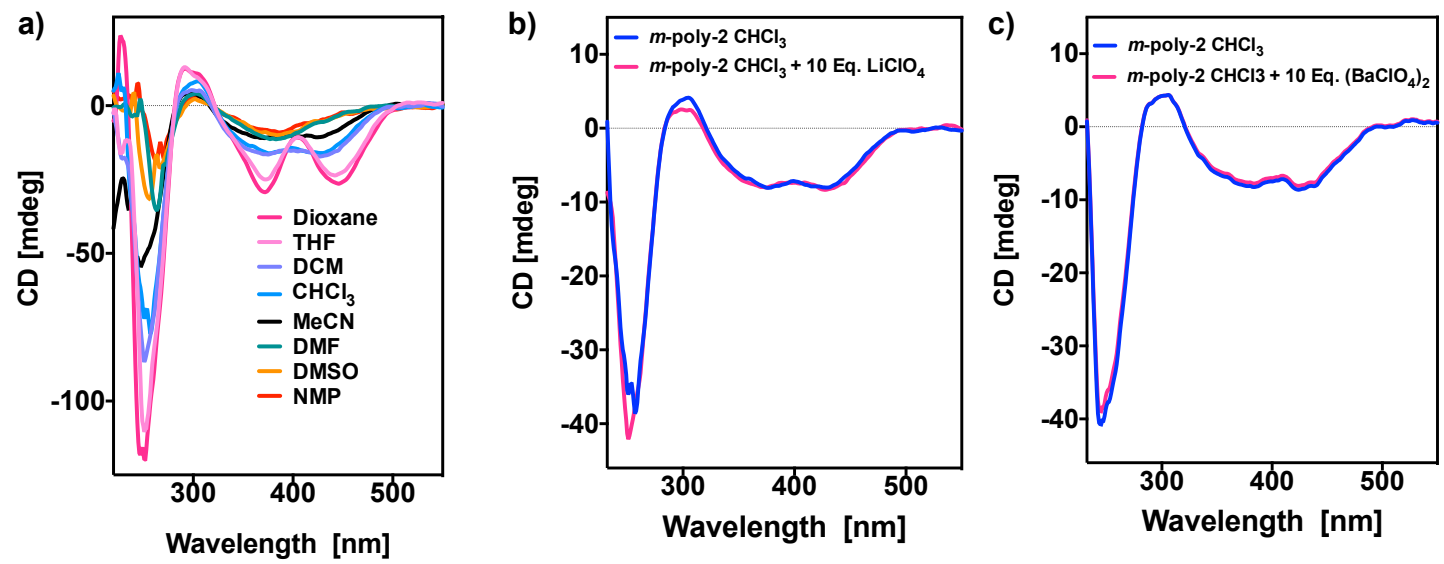

Figure S18. a) CD spectra of $m$-poly-2 in different solvents. b) CD spectra of $m$ poly-2 in $\mathrm{CHCl}_{3}$ before and after the addition of 10 equiv of $\mathrm{LiClO}_{4}$. c) CD spectra of $m$-poly-2 in $\mathrm{CHCl}_{3}$ before and after the addition of 10 equiv of $\mathrm{Ba}\left(\mathrm{ClO}_{4}\right)_{2}$.
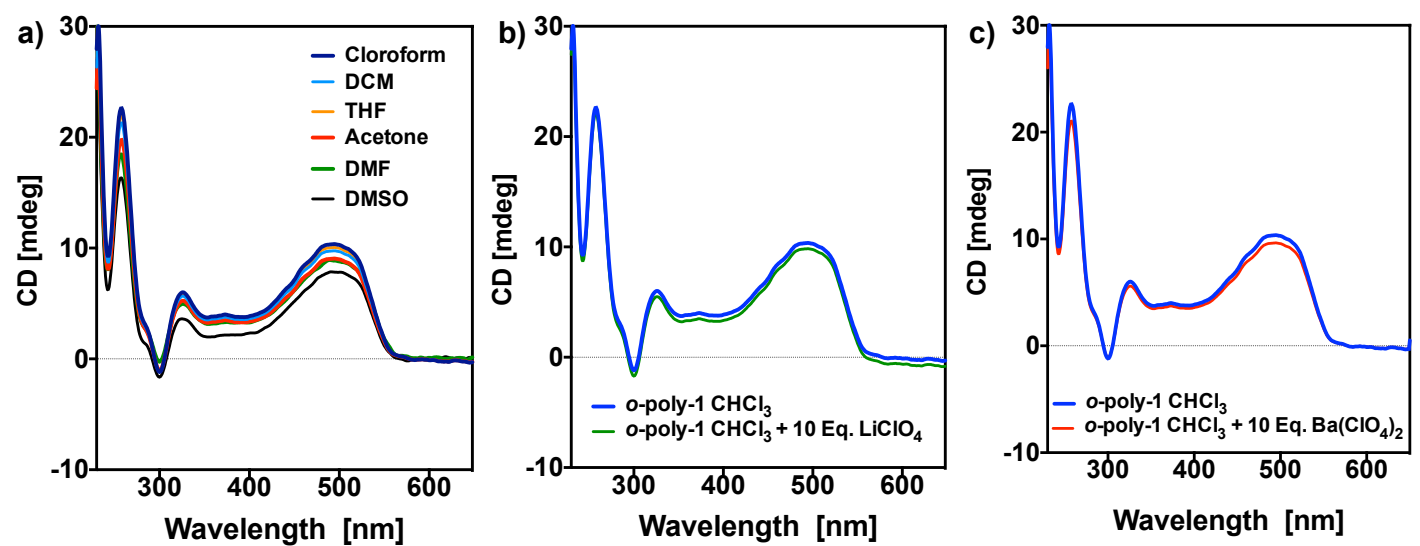

Figure S19. a) CD spectra of $o$-poly-1 in different solvents. b) CD spectra of $o$-poly1 in $\mathrm{CHCl}_{3}$ before and after the addition of 10 equiv of $\mathrm{LiClO}_{4}$. c) $\mathrm{CD}$ spectra of $o$ poly-1 in $\mathrm{CHCl}_{3}$ before and after the addition of 10 equiv of $\mathrm{Ba}\left(\mathrm{ClO}_{4}\right)_{2}$. 


\section{Supporting References}

S1 F. Freire, J. M. Seco, E. Quiñoá, R. Riguera, Angew. Chem. Int. Ed. 2011, 50, 11692-11696.

S2 I. Louzao, J. M. Seco, E. Quiñoá, R. Riguera, Angew. Chem. Int. Ed. 2010, 49, 1430-1433.

S3 E. Marchal, P. Uriac, B. Legouin, L. Toupet, P. Van der Weghe, Tetrahedron 2007, 63, 9979-9990.

S4 For detailed DSC studies on PPAs see: a) L. Liu, T. Namikoshi, Y. Zang, T. Aoki, S. Hadano, Y. Abe, I. Wasuzu, T. Tsutsuba, M. Teraguchi, T. J. Kaneko, J. Am. Chem. Soc., 2013, 135, 602-605. b) S. Leiras, F. Freire, J. M. Seco, E. Quiñoá, R. Riguera, Chem. Sci., 2013, 4, 2735-2743.

S5 R. Rodríguez, J. Ignés-Mullol, F. Sagués, E. Quiñoá, R. Riguera, F. Freire, Nanoscale, 2016, 8, 3362-3367. 